\title{
Terra, território e América Latina: o desafio de cultivar a esperança
}

\author{
Gilberto de Souza Marques ${ }^{1}$ \\ https://orcid.org/0000-0003-0400-1337 \\ ${ }^{1}$ Universidade Federal do Pará, Instituto de Ciências Sociais Aplicadas, Programa de Pós-graduação em Economia, PA, Brasil
}

Enquanto este número da Revista Katálysis já estava sendo elaborado, algo acontecia em Jacareacanga, Sudoeste do Pará, fronteira com Amazonas e Mato Grosso. No dia 26 de maio de 2021 um áudio começou a circular nas redes sociais locais e logo alcançou outras regiões: "Chegaram na minha casa. Vão queimar tudo aqui. Um grupo muito grande". A voz era de Maria Leusa Munduruku, liderança indígena, que, para defender o território de seu povo, enfrenta madeireiros, fazendeiros e, recentemente, principalmente garimpeiros ilegais. A casa de sua família foi queimada. Tiros foram disparados, mas Maria Leusa conseguiu se proteger.

Antes de rumar para a aldeia, os garimpeiros já haviam enfrentado a polícia federal que estava no município para combater garimpo ilegal de ouro. Tentaram expulsar o contingente da PF e Ibama que estava na cidade. Em 2020, em Jacareacanga havia sido promovido o "dia do fogo", em que proprietários rurais e grileiros organizaram para tocar fogo em grande quantidade na floresta.

Em Roraima, entre 10 de maio e meados de junho de 2021, indígenas da Terra Yanomami sofreram pelo menos 23 ataques de garimpeiros, que usaram bombas de gás, fuzis e outros armamentos.

Os atentados em Jacarecanga e Roraima são a expressão do momento político que o Brasil atravessa, onde o Presidente da República estimula grileiros e garimpeiros a destruírem as florestas e seus povos.

Em 2020, o Pantanal sofreu com incêndios muito intensos, fazendo com que se levem vários anos para que o bioma se recupere. Foi a maior ocorrência de incêndios desde que o Instituto Nacional de Pesquisas Espaciais (INPE) começou a fazer esse monitoramento em 1998.

Desde a primeira metade dos anos 2000, os dados sobre o desmatamento na Amazônia brasileira vinham se reduzindo, mas a partir de 2013, seguindo a crise político-econômica do Brasil, essa dinâmica se inverteu. Isso evidencia o caráter predatório-especulativo em torno do desmatamento: historicamente, cresce em momentos de instabilidade ou de possibilidade de transição política.

Quase todos os meses do primeiro semestre de 2021 registraram algum recorde de desmatamento na Amazônia em relação aos meses dos anos anteriores. Segundo o INPE (2021), entre janeiro e 25 junho desse ano, o desmatamento na Amazônia Legal (região Norte mais Mato Grosso e Maranhão) foi o maior dos últimos 6 anos, equivalendo a duas cidades de São Paulo.

De acordo com o Instituto do Homem e Meio Ambiente da Amazônia (IMAZON, 2021), apenas em junho de 2021 o desmatamento na região $\left(926 \mathrm{~km}^{2}\right)$ foi quase três vezes a área da cidade de Fortaleza. Nos onze meses anteriores, incluindo junho, o desmatamento acumulado $\left(8.381 \mathrm{~km}^{2}\right)$ se expandiu $51 \%$. O mais preocupante é que a comparação é com períodos que já sofreram expansão.

Este é um artigo publicado em acesso aberto (Open Access) sob a licença Creative Commons Attribution Non-

Commercial, que permite uso, distribuição e reprodução em qualquer meio, sem restrições desde que sem fins comerciais e que o trabalho original seja corretamente citado. 
O Imazon constatou ainda que $63 \%$ desse desmatamento ocorreu em terras privadas ou sob algum estágio de posse, seguido por assentamentos, unidades de conservação e terras indígenas.

Nos primeiros meses de 2020, o INPE já havia constatado que aproximadamente $40 \%$ do desmatamento na Amazônia havia sido concentrado em áreas de conservação e terras indígenas.

O primeiro decreto do governo do Pará restringindo circulação de pessoas e atividades administrativas e comerciais em função da Covid-19 foi publicado em 16 de março de 2020. Analisando os dados até 13 de maio de 2020 (menos de dois meses depois), constatamos que em algumas áreas de conservação e terras indígenas o desmatamento concentrou-se $100 \%$ logo após o decreto.

O que esses dados revelam? Primeiro, aproveitando os estímulos do governo brasileiro (cujo exemplo é o desmonte de instituições como o Ibama), os grandes proprietários de terra expandem o desmatamento para além do permitido, reduzindo a reserva legal estabelecida pela legislação. Segundo, aproveitando a Covid-19 (com a diminuição da fiscalização ambiental e o autoisolamento de comunidades tradicionais como proteção contra a doença), grileiros avançam sobre terras públicas e indígenas, apropriando-se das mesmas. Seguem um movimento conhecido: apropriam-se ilegalmente da terra, negociam a extração da madeira e, conseguindo alguma documentação provisória legal ou forjada, vendem a "propriedade" para pecuaristas (que as regularizam sob o argumento de tê-las adquirido de boa-fé) cujo gado, de alguma forma, entra no circuito dos grandes frigoríficos.

Especulação fundiária é a antessala da expansão bovina que, por sua vez, contribui para a acumulação ampliada do capital vinculado às redes nacional e transnacional de processamento e comercialização de proteína animal. A Amazônia Legal brasileira é a região com maior rebanho bovino do Brasil, com 89.592 .473 de cabeças em 2019, afora bubalinos e equinos. Como nesse ano a população total residente estimada da região, segundo o IBGE (2021), foi de 28.990.627 pessoas, constatamos que há mais de três bois para cada habitante amazônico.

Nesse processo, não apenas a floresta é degradada, mas o próprio ser humano. Povos nativos são profundamente agredidos e a derrubada da floresta em muitos casos recorre ao trabalho escravo (e outras formas de trabalho degradante) como meio para reduzir os custos da apropriação ilícita da terra e de sua inclusão nos circuitos do agronegócio.

Essa agressão assume dimensões de catástrofe (produzida pelo capital). Um estudo com pesquisadores do INPE (GATTI, et al. 2021) estimou que, em função dos desmatamento-incêndio, a Amazônia já está emitindo mais gás carbônico do que consegue capturar da atmosfera. Esse é o gás que mais tem provocado o aquecimento global, que em julho de 2021 fez com que a Columbia Britânica (Canadá), estado tradicionalmente gélido, atingisse $49,6^{\circ} \mathrm{C}$.

Desmatamento também vem acompanhado de conflitos, particularmente fundiários. Segundo a CPT (2021), ocorreram 2.054 conflitos no campo brasileiro em 2020, atingindo diretamente 914.144 pessoas. Uma década antes, em 2011, havia sido 1.390 casos e 636.340 pessoas envolvidas. Entre os diversos tipos, os conflitos por terra sobressaem. Em 2011 foram 818 casos e em 2020 saltaram para 1.576 ocorrências. A Amazônia Legal concentra esses conflitos, seguida por Nordeste e Sudeste.

Ocorre, então, aquilo que Altvater (1995) nomina como entropia social, uma acelerada apropriação da natureza que amplia as contradições e degradação da sociedade. Ditado pela lógica do lucro, o ritmo de apropriação da natureza se acelera muito mais que o tempo que ela necessita para se recompor. Os dois ritmos se tornam incompatíveis e isso se evidencia na atual problemática ambiental mundial.

Terras, floresta, rios (na forma de hidrelétrica, por exemplo), solo e subsolo estão sendo consumidos a tal velocidade que o seu esgotamento fica muito mais rápido. É o que acontece com a maior província mineral do planeta, Carajás, no Sudeste paraense. A companhia Vale levou 23 anos para extrair seu primeiro 1 bilhão de toneladas de ferro da província, mas somente em 2020 de lá se extraiu 192,3 milhões de toneladas do minério. Em ritmo crescente, em apenas cinco anos se extrai 1 bilhão de toneladas de ferro.

Isso tudo se configura naquilo que Harvey (2004), partindo de Marx (1988), caracterizou como acumulação por espoliação e reforça o que a Teoria Marxista da Dependência definiu como dependência (MARINI, 2005) - entendida como a condição em que uma nação se alimenta (se apropria) de parte do valor produzido por outra nação/região. Esta, por sua vez, sofre com o aumento das contradições sociais e da própria dependência. Assim, dependência gera mais dependência.

À exceção do Amazonas, todos os demais estados da Amazônia legal brasileira têm sua balança comercial dominada por produtos básicos, sem industrialização, configurando uma economia primário-exportadora. Pará 
e Mato Grosso estão entre os maiores saldos da balança comercial brasileira. O primeiro, com o predomínio dos minérios, tem em torno de $80 \%$ das suas exportações na forma de produtos básicos. Já no Mato Grosso, hegemonizado pela soja, esse percentual supera $90 \%$.

Essa não é uma exclusividade amazônica. O Brasil caminha para trás em sua configuração produtiva. Segundo o Ministério da Economia (BRASIL, 2021), de janeiro a junho de 2021, os três produtos que dominaram as exportações brasileiras foram soja (18\%), ferro bruto (16\%) e óleos brutos (petróleo bruto, $11 \%$ ).

Todos esses empreendimentos carregam consigo uma promessa de desenvolvimento. Mas para quem? Já passou a hora de questionarmos essas promessas e as teorias que as sustentam (MARQUES, 2019).

O governo Bolsonaro e seus aliados tentam regularizar a mineração sobre terras indígenas. Enquanto não conseguem, estimulam essas atividades, mesmo que ilegalmente, tentando "passar a boiada", ainda que na marra.

Nas terras munduruku, do Sudeoeste paraense, existem mais de 400 pontos de extração ilegal de ouro, alguns com grande maquinário. Esse foi o motivo principal da tentativa de assassinato da liderança Munduruku: a luta contra os garimpos. Maria Leusa é a expressão de outra Amazônia, Brasil e América Latina, de outra relação sociedade-natureza. Expressa luta, resistência, floresta, vida e esperança.

Enquanto os governos petistas (Lula e Dilma) buscavam construir megahidrelétricas no rio Tapajós, retardando a regularização de terras indígenas na região, seu povo, como resistência, fez a autodemarcação de seu território. Em 2017, durante o encontro das mulheres Munduruku, decidiu-se ocupar os canteiros de obra da hidrelétrica São Manoel, no rio Teles Pires (Mato Grosso), afluente do Tapajós. Todo o povo Munduruku as seguiu. Qual o motivo da ocupação? Reparações, devolução das urnas funerárias e exigência de que a empresa pedisse desculpas por ter violado o território sagrado, onde estavam enterrados seus ancestrais.

Processos de luta e organização social riquíssimos estão em curso. Os Ka'apor, no Maranhão, organizaram sua guarda de autodefesa, colocando para fora de seu território todos os invasores. Outros povos indígenas também criaram guardas semelhantes. É o caso dos Guardiões da Floresta (Guajajara).

No final de agosto de 2019 um encontro reuniu 14 etnias indígenas e ribeirinhos de 4 reservas da bacia do rio Xingu. Algumas etnias historicamente haviam sido adversárias, chegando a realizar guerras entre si. Foi o caso dos Paraná e Kayapó, esses últimos os anfitriões do encontro. Ao final, Mudjire Kayapó, sintetizou o resultado: "Hoje nós temos um só inimigo, que é o governo do Brasil, o presidente do Brasil, e as invasões de não indígenas. Temos brigas internas, mas, para lutar contra este governo, a gente se junta" (BBC NEWS, 2019).

No Pará há resistência ribeirinha contra a construção do porto da Cargill em Abaetetuba e contra novos empreendimentos logísticos em Barcarena. Nos demais estados há muita luta indígena e camponesa, como é o caso da Liga dos Camponeses Pobres de Rondônia.

Indígenas e camponeses mexicanos, bolivianos, chilenos, equatorianos e colombianos, entre outros, impulsionam ricos processos de organização social, chegando até mesmo a pensar a sociedade sob outros paradigmas, como é o caso do bem viver. Em alguns países, esses movimentos foram parte ativa fundamental para derrotar projetos golpistas, governos e setores de direita. Foi o caso da Bolívia e do Chile, por exemplo.

Não queremos esconder as contradições e os processos de saque, mas evidenciar que há lutas e fenômenos que alimentam nossa esperança.

Todos esses movimentos e, particularmente, suas lideranças vivem sob o risco do assassinato e outras formas de violência. Porém, eles ainda têm muito a fazer, a viver e mais ainda a nos ensinar. É por isso que podemos parafrasear o músico cearense Belchior que na canção Coração Selvagem diz que seu coração é frágil, mas tem uma enorme pressa de viver.

Essas lideranças têm essa pressa. É o caso de Erasmo Alves Theófilo, 33 anos, cadeirante e liderança camponesa de Anapu-PA, município da Volta Grande do rio Xingu, região onde se construiu a hidrelétrica Belo Monte. O município ficou conhecido em função do assassinato da missionária Dorothy Stang, em 2005.

Erasmo organiza trabalhadores que resistem aos grileiros de terra, que conformam o "consórcio da morte" na região. Já sofreu três atentados à sua vida. Ele nos diz pessoalmente: "Eu não quero morrer. Ainda tenho muito a fazer". De fato, tem. Além da luta camponesa, quer ver crescer seu mais novo filho, Eduardo, com apenas quatro meses de idade. É no sorriso do pequeno Eduardo que Erasmo busca forças para sobreviver aos atentados e cultivar a esperança, mesmo quando o terreno se encontra árido.

O que expusemos aqui é o pano de fundo deste número da Katálysis, cujo tema principal é Terra, Território e América Latina, temática mais que atual em plena terceira década do século XXI. Experiências de países 
latino-americanos, questão ambiental, negra, de mulheres, camponesa, mineração e trabalho fazem parte das reflexões nos vários artigos. São elaborações diversas, densas, ilustrativas e problematizadoras.

Esperamos que contribuam para enriquecer o debate, nossas reflexões e o desejo ativo de mudar o cenário atual, nos permitindo visualizar o florescer de um horizonte de liberdade e igualdade social. Boa leitura.

Belém-PA, 30 de julho de 2021.

\section{Referências}

ALTVATER, Elma. O preço da riqueza. São Paulo: Unesp, 1995.

BBC NEWS. https://www.bbc.com/portuguese/brasil-49528317. Acessado em 28.07.2021.

BRASIL. Ministério da Economia. https://www.gov.br/produtividade-e-comercio-exterior/pt-br. Acessado em 28.07.2021.

CPT. Conflitos no campo: Brasil 2020. Goiânia: CPT Nacional, 2021.

GATTI, L.V., BASSO, L.S., MILLER, J.B. et al. Amazonia as a carbon source linked to deforestation and climate change. Nature 595, 388-393 (2021). https://doi.org/10.1038/s41586-021-03629-6

HARVEY, David. O Novo Imperialismo. São Paulo: Edições Loyola, 2004.

IBGE. https://www.ibge.gov.br/estatisticas/sociais/populacao/9109-projecao-da-populacao.html?=\&t=o-que-e. Acessado em 28.07.2021. IMAZON. imazon.org.br. Acessado em 28.07.2021.

INPE. inpe.br. Acessado em 28.07.2021.

MARINI, Ruy M. Dialética da Dependência. In: STEDILE, João P. e TRASPADINI, Roberta (orgs). Ruy Mauro Marini: vida e obra. São Paulo: Expressão Popular, 2005.

MARQUES, Gilberto. Amazônia: riqueza, degradação e saque. São Paulo: Expressão Popular, 2019.

MARX, Karl. O Capital. São Paulo: Nova Cultural, 1988.

\section{Gilberto de Souza Marques}

gilsm@ufpa.br

Doutor pelo Programa de Pós-Graduação de Ciências Sociais em Desenvolvimento, Agricultura e Sociedade da Universidade Federal Rural do Rio de Janeiro (CPDA/UFRRJ).

Professor da Faculdade e do Programa de Pós-Graduação em Economia da Universidade Federal do Pará (UFPA).

\section{UFPA}

Rua Augusto Corrêa, 1, Guamá.

Belém -Pará - Brasil.

CEP 66.075-110 